\title{
Penerapan Clustering dalam Mengelompokkan Jumlah Kunjungan Wisatawan Mancanegara Dengan Metode $K$-Means
}

\author{
Edy Satria1, Heru Satria Tambunan², Ilham Syahputra Saragih ${ }^{3}$, Irfan Sudahri Damanik ${ }^{4}$, Fany \\ Than Ervina Sitanggang 5 \\ 1,5 Mahasiswa STIKOM Tunas Bangsa \\ 2,3,4STIKOM Tunas Bangsa \\ Jl. Jend Sudirman Blok A No. 13 Pematangsiantar, Kode Pos: 21127 Sumatera Utara Indonesia \\ Email : edysatria959@gmail.com
}

\begin{abstract}
The Indonesian tourism sector currently contributes approximately 4\% of the total economy. In 2019, the Indonesian Government wants to increase this figure to double to 8\% of PDB (Produk Domestik Bruto), a target that implies that within the next 4 years, the number of visitors needs to be doubled to approximately 20 million tourists. This study discusses the Application of Clustering in Grouping the Number of Foreign Tourist Visits by Nationality and Month of Arrival by the K-Means Method. The source of this research data was collected based on data on the number of foreign tourist visits produced by the National Statistics Agency. K-Means clustering is one of the data mining techniques that gives a description of an item's cluster. The purpose of this study is to classify the number of foreign tourists in Indonesia. The results of this study are grouping the number of foreign tourist visits grouped by two clusters (high and low), high clusters of 4 countries and low clusters of 87 countries. Countries that are included in the lower clusters can be used for the Government of Indonesia in terms of improving existing facilities in tourist attractions so that visiting tourists will increase in the future.
\end{abstract}

Keywords: Foreign Tourists, Data Mining, K-Means, BPS

Abstrak - Sektor pariwisata Indonesia saat ini berkontribusi kira-kira 4\% dari total perekonomian. Pada tahun 2019, Pemerintah Indonesia ingin meningkatkan angka ini dua kali lipat menjadi 8\% dari PDB (Produk Domestik Bruto), sebuah target yang mengimplikasikan bahwa dalam waktu 4 tahun mendatang, jumlah pengunjung perlu ditingkatkan dua kali lipat menjadi kira-kira 20 juta wisatawan. Penelitian ini membahas tentang Penerapan Clustering Dalam Mengelompokkan Jumlah Kunjungan Wisatawan Mancanegara Menurut Kebangsaan Dan Bulan Kedatangan Dengan Metode K-Means. Sumber data penelitian ini dikumpulkan berdasarkan data jumlah kunjungan Wisatawan Mancanegara yang dihasilkan oleh Badan Pusat Statistik Nasional. K-Means Clustering merupakan salah satu teknik data mining yang memberikan deskripsi cluster sebuah item. Tujuan dari penelitian ini untuk mengelompokkan jumlah Wisatawan Mancanegara yang di Indonesia. Hasil dari penelitian ini yaitu pengelompokan jumlah kunjungan Wisatawan Mancanegara yang dikelompokkan dengan dua cluster (tinggi dan rendah), cluster tinggi 4 negara dan cluster rendah 87 Negara. Negara yang termasuk cluster rendah dapat dijadikan kontribusi untuk Pemerintah Indonesia dalam hal peningkatan fasilitas yang ada di tempat wisata agar turis asing yang berkunjung akan semakin meningkat dimasa yang akan datang.

Kata kunci: Wisatawan Mancanegara, Data Mining, K-Means, BPS 


\section{PENDAHULUAN}

Wisatawan adalah orang yang mengadakan perjalanan dari tempat kediamannya tanpa menetap ditempat yang didatanginya, atau hanya untuk sementara waktu yang ditempat tinggal didatanginya. Mereka yang dianggap wisatawan adalah orang yang melakukan kesenangan. Wisatawan adalah orangorang yang melakukan kegiatan wisata (Undang-undang nomor 10 tahun 2009) [1]. Untuk meningkatkan kualitas pariwisata, tentu perlu dukungan dari berbagai pihak. Segala bentuk dukungan sudah semestinya diperlukan dalam hal pengelolaan tempat yang memiliki potensi atau sudah menjadi lokasi pariwisata. Melihat kunjungan para Wisatawan Mancanegara setiap tahun meningkat, pemerintah Indonesia harus mengerti apa kebutuhan para Wisatawan Mancanegara tersebut supaya tetap datang mengunjungi objek wisata-wisata Indonesia dan fasilitas-fasilitas apa yang harus dikembangkan. Sumber data penelitian ini dikumpulkan berdasarkan data jumlah kunjungan Wisatawan Mancanegara yang dihasilkan oleh Badan Pusat Statistik Nasional. Badan Pusat Statistik adalah Lembaga Pemerintah Non Kementerian yang bertanggung jawab langsung kepada Presiden. Sebelumnya, BPS merupakan Biro Pusat Statistik, yang dibentuk berdasarkan UU Nomor 6 Tahun 1960 tentang Sensus dan UU Nomor 7 Tahun 1960 tentang Statistik. Sebagai pengganti kedua UU tersebut ditetapkan UU Nomor 16 Tahun 1997 tentang Statistik.

Berdasarkan latar belakang tersebut, diperlukan pengelompokan dengan menggunakan tekhnik data mining yaitu K-Means. K-Means merupakan suatu algoritma yang digunakan dalam pengelompokkan secara pertisi yang memisahkan data ke dalam kelompok yang berbeda - beda. Algoritma ini mampu meminimalkan jarak antara data ke clusternya. Pada dasarnya penggunaan algoritma ini dalam proses clustering tergantung pada data yang didapatkan dan konklusi yang ingin dicapai di akhir proses [2]. Adapun penelitian terdahulu yang berjudul "Penerapan Data Mining Dalam Mengelompokkan Kunjungan Wisatawan Ke Objek Wisata Unggulan Di Prov. DKI Jakarta Dengan K-Means"[3]. Diharapkan penelitian ini dapat dijadikan kontribusi untuk Pemerintah Indonesia dalam hal peningkatan fasilitas yang ada di tempat wisata, dukungan pelatihan peningkatan layanan dan kinerja serta dukungan sosialisasi lokasi wisata agar turis asing yang berkunjung akan semakin meningkat dimasa yang akan datang, serta pemerataan objek wisata yang ada di Indonesia dalam hal pembangunan.

\section{METODOLOGI PENELITIAN}

\subsection{Metode Penelitian}

Metode penelitian adalah langkah yang dimiliki dan dilakukan oleh peneliti dalam rangka untuk mengumpulkan informasi atau data serta melakukan investigasi pada data yang telah didapatkan tersebut. Metode penelitian memberikan gambaran rancangan penelitian yang meliputi antara lain: metode pengumpulan data, analisa data, sumber data, kontribusi penelitian, lokasi penelitian dan waktu pengumpulan data. 


\subsection{Metode Pengumpulan Data}

Pengumpulan data dilakukan untuk memperoleh informasi yang dibutuhkan dalam rangka mencapai tujuan penelitian. Berikut beberapa hal yang dilakukan penulis dalam mengumpulkan data, yaitu sebagai berikut :

1. Data penelitian ini diperoleh dari situs resmi bps.go.id (https://www.bps.go.id/dynamictable/2018/07/30/1548/jumlah-kunjunganwisman-menurut-kebangsaan-dan-bulan-kedatangan-tahun-2017---2018.html) atau Badan Pusat Statistik, yang merupakan Lembaga Pemerintah Non Kementerian yang bertanggung jawab langsung kepada Presiden.

2. Dalam penelitian ini penulis melihat referensi-referensi berupa buku dan jurnal untuk memudahkan penulis dalam menyelesaikan karya tulis yang dilakukan.

\subsection{Analisis Data}

Analisis data adalah upaya atau cara untuk mengolah data menjadi informasi sehingga karakteristik data tersebut bisa dipahami dan bermanfaat untuk solusi permasalahan, tertutama masalah yang berkaitan dengan penelitian. Proses analisa data bisa dilakukan setelah adanya pengumpulan data. Pengumpulan data yang digunakan penulis untuk mendukung terlaksananya penelitian ini adalah Data sekunder. Data sekunder adalah sumber data penelitian yang diperoleh melalui media perantara atau secara tidak langsung yang berupa buku, catatan, bukti yang telah ada, atau arsip baik yang dipublikasikan maupun yang tidak dipublikasikan secara umum. Data yang diperoleh dari penelitian ini adalah melalui situs resmi bps.go.id atau Badan Pusat Statistik, yakni data jumlah kunjungan Wisatawan Mancanegara.

\subsection{Analisis Permasalahan}

Penulis dapat menyimpulkan bahwa permasalahan yang menjadi dasar dilakukannya penelitian ini adalah bagaimana mengembangkan potensi wisata agar Wisatawan Mancanegara yang berkunjung akan semakin meningkat dimasa yang akan datang.

\subsection{Metode $K$-MEANS}

Algoritma K-Means merupakan metode yang digunakan untuk mengelompokkan suatu data yang dilakukan berdasarkan pencarian pusat cluster secara iteratif dimana letak cluster masing-masing data ditemukan jarak minimum setiap data pada pusat cluster. 


\subsection{Kerangka Penelitian}

Berikut adalah diagram blok yang menjelaskan alur kerja penelitian:

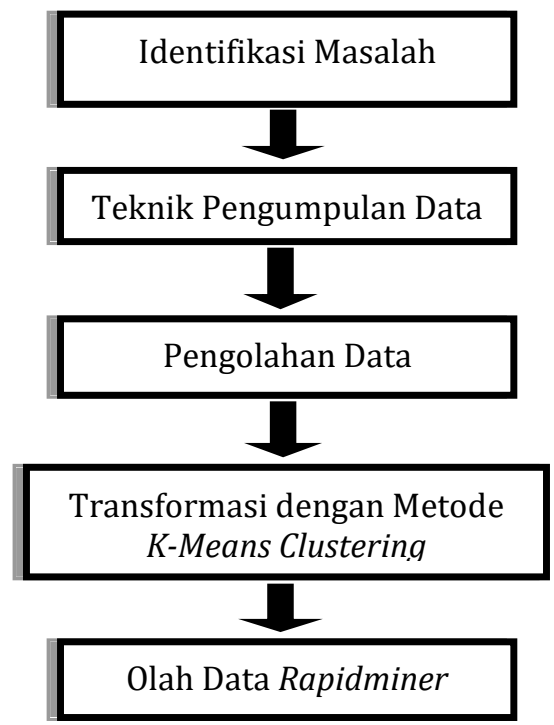

Gambar 1. Diagram Blok Alur Kerja Penelitian

\subsection{Perhitungan Manual Metode K-MEANS CLUSTERING}

Pada tahap ini adalah proses perhitungan manual dengan menggunakan rumus Metode K-Means Clustering. Berikut adalah langkah-langkah penyelesaian yang dilakukan penulis dalam mengelompokkan jumlah Wisatawan Mancanegara yang berkunjung ke Indonesia pada tahun 2017/2018 yang diperoleh dari situs Badan Pusat Statistik menggunakan algoritma K-Means.

1. Menentukan data yang akan di cluster

Tabel di bawah merupakan data yang akan di proses dengan metode K-Means Clustering.

Tabel 1. Data Jumlah Kunjungan Wisatawan Mancanegara Tahun 2017/2018

\begin{tabular}{|c|l|r|r|}
\hline No & $\begin{array}{c}\text { Kebangsaan } \\
\text { (A) }\end{array}$ & $\begin{array}{c}\text { Tahun } \\
\mathbf{2 0 1 7} \\
(\mathbf{X})\end{array}$ & $\begin{array}{c}\text { Tahun } \\
\mathbf{2 0 1 8} \\
(\mathbf{Y})\end{array}$ \\
\hline 1 & Afganistan & 595 & 1034 \\
\hline 2 & Albania & 592 & 706 \\
\hline 3 & Armenia & 772 & 794 \\
\hline 4 & Austria & 27208 & 26676 \\
\hline 5 & Azerbaijan & 4405 & 1138 \\
\hline 6 & Bahrain & 2457 & 2208 \\
\hline 7 & Bangladesh & 56503 & 50423 \\
\hline 8 & Belarus & 4576 & 4340 \\
\hline 9 & Belgium & 48477 & 47693 \\
\hline 10 & Bhutan & 610 & 594 \\
\hline 11 & Bosnia & 1784 & 982 \\
\hline
\end{tabular}

\begin{tabular}{|r|l|r|r|}
\hline No & $\begin{array}{l}\text { Kebangsaan } \\
(\mathbf{A})\end{array}$ & $\begin{array}{c}\text { Tahun } \\
\mathbf{2 0 1 7} \\
(\mathbf{X})\end{array}$ & $\begin{array}{c}\text { Tahun } \\
\mathbf{2 0 1 8} \\
(\mathbf{Y})\end{array}$ \\
\hline 12 & $\begin{array}{l}\text { Brunei } \\
\text { Darussalam }\end{array}$ & 23455 & 14394 \\
\hline 13 & Bulgaria & 8695 & 6908 \\
\hline 14 & Canada & 96139 & 89533 \\
\hline 15 & China & 209317 & 199415 \\
& 1 & 9 \\
\hline 16 & Croasia & 6620 & 3723 \\
\hline 17 & Cyprus & 1909 & 1815 \\
\hline 18 & Czech & 19904 & 20250 \\
\hline 19 & Denmark & 43721 & 44140 \\
\hline 20 & Egypt & 20345 & 16297 \\
\hline 21 & Estonia & 7569 & 7039 \\
\hline 22 & Finland & 24447 & 24230 \\
\hline 23 & France & 274117 & 275020 \\
\hline 24 & Georgia & 1265 & 587 \\
\hline 25 & Germany & 267823 & 257233 \\
\hline
\end{tabular}

Mengelompokkan Jumlah Kunjungan Wisatawan Mancanegara dengan K-Means (Edy Satria) | 465 


\begin{tabular}{|c|c|c|c|}
\hline No & $\begin{array}{c}\text { Kebangsaan } \\
\text { (A) }\end{array}$ & $\begin{array}{c}\text { Tahun } \\
2017 \\
\text { (X) }\end{array}$ & $\begin{array}{c}\text { Tahun } \\
2018 \\
\text { (Y) }\end{array}$ \\
\hline 26 & Hong Kong & 98272 & 84825 \\
\hline 27 & Hongaria & 12600 & 12488 \\
\hline 28 & It aly & 90022 & 89411 \\
\hline 29 & $\begin{array}{l}\text { Iceland } \\
\text { (Islandia) }\end{array}$ & 4776 & 2232 \\
\hline 30 & India & 536902 & 535550 \\
\hline 31 & Irak & 2167 & 2189 \\
\hline 32 & Iran & 16301 & 11029 \\
\hline 33 & $\begin{array}{l}\text { Irlandia } \\
\text { (Ireland) }\end{array}$ & 29400 & 25972 \\
\hline 34 & Israel & 688 & 460 \\
\hline 35 & Japan & 573310 & 485888 \\
\hline 36 & Jordan & 6773 & 5726 \\
\hline 37 & Kamboja & 6506 & 7950 \\
\hline 38 & Kazakhstan & 7219 & 6671 \\
\hline 39 & Kirgistan & 1254 & 1147 \\
\hline 40 & Korea Utara & 140 & 608 \\
\hline 41 & Kuwait & 5760 & 5199 \\
\hline 42 & Laos & 4036 & 3577 \\
\hline 43 & Latvia & 3932 & 3873 \\
\hline 44 & Libanon & 6115 & 4868 \\
\hline 45 & Lithuania & 8550 & 7790 \\
\hline 46 & Luxemburg & 1720 & 1976 \\
\hline 47 & Macao & 618 & 294 \\
\hline 48 & Macedonia & 1381 & 944 \\
\hline 49 & Maladewa & 2668 & 2204 \\
\hline 50 & Malaysia & $\begin{array}{r}212188 \\
8\end{array}$ & $\begin{array}{r}225511 \\
5\end{array}$ \\
\hline 51 & Malta & 2173 & 1181 \\
\hline 52 & Moldova & 1030 & 738 \\
\hline 53 & Mongolia & 2414 & 2992 \\
\hline 54 & $\begin{array}{l}\text { Myanmar/Bur } \\
\text { ma }\end{array}$ & 48133 & 25320 \\
\hline 55 & Nepal & 12821 & 13630 \\
\hline 56 & Netherlands & 210426 & 196169 \\
\hline 57 & Norway & 22838 & 23155 \\
\hline 58 & Oman & 18615 & 24366 \\
\hline 59 & Pakistan & 11424 & 12107 \\
\hline 60 & Palestina & 2035 & 2339 \\
\hline 61 & Philippines & 308977 & 198182 \\
\hline
\end{tabular}

\begin{tabular}{|c|c|c|c|}
\hline No & $\begin{array}{c}\text { Kebangsaan } \\
\text { (A) }\end{array}$ & $\begin{array}{c}\text { Tahun } \\
2017 \\
\text { (X) }\end{array}$ & $\begin{array}{c}\text { Tahun } \\
2018 \\
(Y)\end{array}$ \\
\hline 62 & Polandia & 32704 & 29431 \\
\hline 63 & Portugal & 33223 & 33700 \\
\hline 64 & Qatar & 1859 & 1970 \\
\hline 65 & Rus i a & 117532 & 110028 \\
\hline 66 & Romania & 18787 & 12807 \\
\hline 67 & Saudi Arabia & 182086 & 152569 \\
\hline 68 & $\begin{array}{l}\text { Serbia- } \\
\text { Montenegro }\end{array}$ & 7054 & 3658 \\
\hline 69 & Singapore & $\begin{array}{r}155411 \\
9 \\
\end{array}$ & $\begin{array}{r}152691 \\
8 \\
\end{array}$ \\
\hline 70 & Slovakia & 9264 & 8494 \\
\hline 71 & Slovenia & 5264 & 4149 \\
\hline 72 & South Korea & 423191 & 328471 \\
\hline 73 & Spain & 81690 & 81022 \\
\hline 74 & Srilanka & 35669 & 29709 \\
\hline 75 & Sweden & 51417 & 44041 \\
\hline 76 & Switzerland & 61191 & 56384 \\
\hline 77 & Syiria & 2328 & 1792 \\
\hline 78 & Taiwan & 264278 & 191986 \\
\hline 79 & Tajikhistan & 350 & 488 \\
\hline 80 & Thailand & 138235 & 113565 \\
\hline 81 & Timor Leste & 960026 & $\begin{array}{r}161057 \\
8 \\
\end{array}$ \\
\hline 82 & Turki & 34433 & 19491 \\
\hline 83 & Turkmenistan & 233 & 408 \\
\hline 84 & Ukraine & 32964 & 23468 \\
\hline 85 & $\begin{array}{l}\text { Uni Emirat } \\
\text { Arab }\end{array}$ & 8387 & 6540 \\
\hline 86 & $\begin{array}{l}\text { United } \\
\text { Kingdom }\end{array}$ & 378131 & 362080 \\
\hline 87 & $\begin{array}{l}\text { United States } \\
\text { of America }\end{array}$ & 344766 & 353030 \\
\hline 88 & Uzbekistan & 4057 & 3184 \\
\hline 89 & Vietnam & 77466 & 70963 \\
\hline 90 & Yaman & 8453 & 9036 \\
\hline 91 & $\begin{array}{l}\text { Yunani } \\
\text { (Greece) }\end{array}$ & 9896 & 35 \\
\hline
\end{tabular}

2. Menentukan Jumlah Cluster

Pada tahap ini adalah penulis menetapakan sebanyak 2 (dua) cluster yang akan diterapkan dalam perhitungan manual $K$-Means yaitu cluster tinggi dan rendah. Dari kedua cluster tersebut yang akan di gunakan adalah cluster rendah supaya dapat dijadikan kontribusi kepada pemerintah Indonesia untuk memperhatikan jumlah wisatawan yang berkunjung agar meningkat dimasa yang akan datang.

\section{Menentukan nilai Centroid}

Mengelompokkan Jumlah Kunjungan Wisatawan Mancanegara dengan K-Means (Edy Satria) | 466 
Dalam menentukan nilai Centroid dapat dilakukan dengan cara mencari nilai terbesar dan nilai terkecil dari data yang ada. Pada data kunjungan Wisatawan Mancanegara pada tabel 3.1 diatas penulis menentukan nilai Centroid sebagai berikut.

Tabel 2. Nilai Centroid Data

\begin{tabular}{|l|c|c|}
\hline C1/x (Max) & 2121888 & 2255115 \\
\hline C2/y (Min) & 140 & 294 \\
\hline
\end{tabular}

4. Menghitung Jarak Centroid

Untuk menghitung jarak Centroid dapat dilakukan dengan menggunakan persamaan dibawah :

$$
D e=\sqrt{(x i-s i)^{2}+(y i-t i)^{2}}
$$

Menghitung jarak Centroid 1 (C1) dan Centroid 2 (C2)

$$
\begin{aligned}
& \mathrm{D}_{\mathrm{A} 1 \mathrm{C} 1}=\sqrt{(595-2121888)^{2}+(1034-225115)^{2}}=3095281,11 \\
& \mathrm{D}_{\mathrm{A} 1 \mathrm{C} 2}=\sqrt{(595-140)^{2}+(1034-294)^{2}}=868,69
\end{aligned}
$$

Dan seterusnya menggunakan cara yang sama hingga $\mathrm{D}_{\mathrm{A} 91 \mathrm{C} 1}$ dan $\mathrm{D}_{\mathrm{A} 91 \mathrm{C} 2}$ sehingga dihasilkan jarak terpendek dari Centroid. Menghitung jarak terpendek dapat dlilakukan dengan menggunakan rumus $=\mathbf{M I N}(\mathbf{C 1} ; \mathbf{C 2})$ pada MS.Excel. Berikut tabel hasil dari perhitungan Centroid 1 (C1) dan Centroid 2 (C2) serta jarak terpendeknya.

Tabel 3. Jarak Centroid Iterasi 1

\begin{tabular}{|r|r|r|r|}
\hline No & C1 & \multicolumn{1}{c|}{ C2 } & $\begin{array}{c}\text { Jarak } \\
\text { Terpendek }\end{array}$ \\
\hline 1 & 3095281,11 & 868,69 & 868,69 \\
\hline 2 & 3095522,03 & 611,59 & 611,59 \\
\hline 3 & 3095334,60 & 805,87 & 805,87 \\
\hline 4 & 3058369,61 & 37797,97 & 37797,97 \\
\hline 5 & 3092595,44 & 4347,71 & 4347,71 \\
\hline 6 & 3093150,13 & 3005,31 & 3005,31 \\
\hline 7 & 3021006,79 & 75430,13 & 75430,13 \\
\hline 8 & 3090145,34 & 6004,02 & 6004,02 \\
\hline 9 & 3028488,91 & 67698,82 & 67698,82 \\
\hline 10 & 3095591,27 & 557,58 & 557,58 \\
\hline 11 & 3094504,25 & 1782,16 & 1782,16 \\
\hline 12 & 3069894,40 & 27247,00 & 27247,00 \\
\hline 13 & 3085452,86 & 10813,56 & 10813,56 \\
\hline 14 & 2965367,50 & 131070,24 & 131070,24 \\
\hline 15 & 262531,33 & 2890722,47 & 262531,33 \\
\hline 16 & 3089194,82 & 7331,33 & 7331,33 \\
\hline 17 & 3093811,86 & 2332,98 & 2332,98 \\
\hline 18 & 3068054,48 & 28086,61 & 28086,61 \\
\hline 19 & 3034334,94 & 61820,51 & 61820,51 \\
\hline 20 & 3070633,33 & 25774,76 & 25774,76 \\
\hline 21 & 3086128,73 & 10034,19 & 10034,19 \\
\hline 22 & 3062042,89 & 34113,96 & 34113,96 \\
\hline 23 & 2708326,77 & 387991,97 & 387991,97 \\
\hline 24 & 3095147,56 & 1162,53 & 1162,53 \\
\hline 25 & 2725635,62 & 371041,56 & 371041,56 \\
\hline
\end{tabular}

\begin{tabular}{|r|r|r|r|}
\hline No & C1 & \multicolumn{1}{|c|}{ C2 } & $\begin{array}{c}\text { Jarak } \\
\text { Terpendek }\end{array}$ \\
\hline 26 & 2967352,42 & 129519,80 & 129519,80 \\
\hline 27 & 3078712,67 & 17434,03 & 17434,03 \\
\hline 28 & 2969638,57 & 126572,56 & 126572,56 \\
\hline 29 & 3091544,12 & 5024,77 & 5024,77 \\
\hline 30 & 2338607,37 & 758031,95 & 758031,95 \\
\hline 31 & 3093362,68 & 2774,84 & 2774,84 \\
\hline 32 & 3077242,04 & 19401,50 & 19401,50 \\
\hline 33 & 3057381,98 & 38929,52 & 38929,52 \\
\hline 34 & 3095635,41 & 572,59 & 572,59 \\
\hline 35 & 2351224,79 & 751215,94 & 751215,94 \\
\hline 36 & 3087630,54 & 8573,41 & 8573,41 \\
\hline 37 & 3086193,70 & 9956,92 & 9956,92 \\
\hline 38 & 3086636,58 & 9527,77 & 9527,77 \\
\hline 39 & 3094747,21 & 1403,07 & 1403,07 \\
\hline 40 & 3095903,16 & 314,00 & 314,00 \\
\hline 41 & 3088708,42 & 7459,45 & 7459,45 \\
\hline 42 & 3091071,09 & 5094,79 & 5094,79 \\
\hline 43 & 3090926,75 & 5214,26 & 5214,26 \\
\hline 44 & 3088706,36 & 7524,77 & 7524,77 \\
\hline 45 & 3084909,59 & 11265,79 & 11265,79 \\
\hline 46 & 3093824,12 & 2307,71 & 2307,71 \\
\hline 47 & 3095804,28 & 478,00 & 478,00 \\
\hline 48 & 3094808,04 & 1400,92 & 1400,92 \\
\hline 49 & 3093008,47 & 3168,42 & 3168,42 \\
\hline 50 & 0,00 & 3096131,83 & 0,00 \\
\hline
\end{tabular}

Mengelompokkan Jumlah Kunjungan Wisatawan Mancanegara dengan K-Means (Edy Satria) | 467 


\begin{tabular}{|r|r|r|r|}
\hline No & C1 & \multicolumn{1}{c|}{ C2 } & \multicolumn{1}{c|}{$\begin{array}{c}\text { Jarak } \\
\text { Terpendek }\end{array}$} \\
\hline 51 & 3094092,78 & 2218,08 & 2218,08 \\
\hline 52 & 3095198,59 & 994,60 & 994,60 \\
\hline 53 & 3092608,61 & 3528,50 & 3528,50 \\
\hline 54 & 3045069,05 & 54126,04 & 54126,04 \\
\hline 55 & 3077729,46 & 18402,63 & 18402,63 \\
\hline 56 & 2809438,66 & 287379,92 & 287379,92 \\
\hline 57 & 3063928,25 & 32215,28 & 32215,28 \\
\hline 58 & 3065941,68 & 30344,47 & 30344,47 \\
\hline 59 & 3079795,96 & 16336,33 & 16336,33 \\
\hline 60 & 3093343,89 & 2788,02 & 2788,02 \\
\hline 61 & 2741827,80 & 366796,88 & 366796,88 \\
\hline 62 & 3052598,74 & 43696,44 & 43696,44 \\
\hline 63 & 3049132,02 & 47015,38 & 47015,38 \\
\hline 64 & 3093733,24 & 2400,82 & 2400,82 \\
\hline 65 & 2935786,30 & 160693,60 & 160693,60 \\
\hline 66 & 3074244,46 & 22456,31 & 22456,31 \\
\hline 67 & 2860687,24 & 237259,40 & 237259,40 \\
\hline 68 & 3088945,04 & 7688,95 & 7688,95 \\
\hline 69 & 923381,02 & 2178401,15 & 923381,02 \\
\hline 70 & 3083907,60 & 12267,33 & 12267,33 \\
\hline 71 & 3089813,12 & 6412,21 & 6412,21 \\
\hline 72 & 2568565,48 & 535417,87 & 535417,87 \\
\hline
\end{tabular}

\begin{tabular}{|r|r|r|r|}
\hline No & C1 & \multicolumn{1}{c|}{ C2 } & $\begin{array}{c}\text { Jarak } \\
\text { Terpendek }\end{array}$ \\
\hline 73 & 2981457,40 & 114749,35 & 114749,35 \\
\hline 74 & 3050367,45 & 46125,40 & 46125,40 \\
\hline 75 & 3029141,53 & 67402,75 & 67402,75 \\
\hline 76 & 3013451,53 & 82905,44 & 82905,44 \\
\hline 77 & 3093541,52 & 2651,67 & 2651,67 \\
\hline 78 & 2776187,35 & 326365,91 & 326365,91 \\
\hline 79 & 3095846,64 & 285,90 & 285,90 \\
\hline 80 & 2919095,00 & 178607,25 & 178607,25 \\
\hline 81 & 1328665,21 & 1874672,16 & 1328665,21 \\
\hline 82 & 3058673,41 & 39300,57 & 39300,57 \\
\hline 83 & 3095985,08 & 147,12 & 147,12 \\
\hline 84 & 3056771,47 & 40180,21 & 40180,21 \\
\hline 85 & 3085931,95 & 10345,31 & 10345,31 \\
\hline 86 & 2573765,72 & 523226,82 & 523226,82 \\
\hline 87 & 2603092,38 & 493142,74 & 493142,74 \\
\hline 88 & 3091342,97 & 4867,75 & 4867,75 \\
\hline 89 & 2991685,36 & 104754,08 & 104754,08 \\
\hline 90 & 3084068,48 & 12063,52 & 12063,52 \\
\hline 91 & 3084574,32 & 11830,00 & 11830,00 \\
\hline
\end{tabular}

\section{Menentukan posisi cluster}

Dalam menentukan posisi cluster dari tabel 3.3 diatas, dapat dilakukan dengan melihat pernyataan berikut. "Jika nilai jarak terpendek berada di kolom C1 maka pada tabel posisi cluster, kolom C1 diberi nilai 1" dan "Jika jarak terpendek berada di kolom C2 maka pada tabel posisi cluster, kolom C2 diberi nilai 1". Nilai 1 hanya untuk simbolis atau pertanda bahwa pada kolom tersebut terdapat nilai jarak terpendek mewakili kolom tersebut. Berikut tabel posisi Cluster :

Tabel 4. Posisi Cluster

\begin{tabular}{|c|c|c|}
\hline No & C1 & C2 \\
\hline 1 & & 1 \\
\hline 2 & & 1 \\
\hline 3 & & 1 \\
\hline 4 & & 1 \\
\hline 5 & & 1 \\
\hline 6 & & 1 \\
\hline 7 & & 1 \\
\hline 8 & & 1 \\
\hline 9 & & 1 \\
\hline 10 & & 1 \\
\hline 11 & & 1 \\
\hline 12 & & 1 \\
\hline 13 & & 1 \\
\hline 14 & & 1 \\
\hline 15 & 1 & \\
\hline 16 & & 1 \\
\hline 17 & & 1 \\
\hline 18 & & 1 \\
\hline
\end{tabular}

\begin{tabular}{|c|c|c|}
\hline No & C1 & C2 \\
\hline 47 & & 1 \\
\hline 48 & & 1 \\
\hline 49 & & 1 \\
\hline 50 & 1 & \\
\hline 51 & & 1 \\
\hline 52 & & 1 \\
\hline 53 & & 1 \\
\hline 54 & & 1 \\
\hline 55 & & 1 \\
\hline 56 & & 1 \\
\hline 57 & & 1 \\
\hline 58 & & 1 \\
\hline 59 & & 1 \\
\hline 60 & & 1 \\
\hline 61 & & 1 \\
\hline 62 & & 1 \\
\hline 63 & & 1 \\
\hline 64 & & 1 \\
\hline
\end{tabular}

\begin{tabular}{|c|c|c|c|c|}
\hline 19 & 1 & 65 & & 1 \\
\hline 20 & 1 & 66 & & 1 \\
\hline 21 & 1 & 67 & & 1 \\
\hline 22 & 1 & 68 & & 1 \\
\hline 23 & 1 & 69 & 1 & \\
\hline 24 & 1 & 70 & & 1 \\
\hline 25 & 1 & 71 & & 1 \\
\hline 26 & 1 & 72 & & 1 \\
\hline 27 & 1 & 73 & & 1 \\
\hline 28 & 1 & 74 & & 1 \\
\hline 29 & 1 & 75 & & 1 \\
\hline 30 & 1 & 76 & & 1 \\
\hline 31 & 1 & 77 & & 1 \\
\hline 32 & 1 & 78 & & 1 \\
\hline 33 & 1 & 79 & & 1 \\
\hline 34 & 1 & 80 & & 1 \\
\hline 35 & 1 & 81 & 1 & \\
\hline 36 & 1 & 82 & & 1 \\
\hline 37 & 1 & 83 & & 1 \\
\hline
\end{tabular}

Mengelompokkan Jumlah Kunjungan Wisatawan Mancanegara dengan K-Means (Edy Satria) | 468 


\begin{tabular}{|l|l|l|l|l|l|l|}
\hline 38 & & 1 \\
\hline 39 & & 1 \\
\hline 40 & & 1 \\
\hline 41 & & 1 \\
\hline 42 & & 1 & 84 & & 1 \\
\hline & & 85 & & 1 \\
\hline 86 & & 1 \\
\hline & 87 & & 1 \\
\hline
\end{tabular}

\begin{tabular}{|l|l|l|}
\hline 43 & & 1 \\
\hline 44 & & 1 \\
\hline 45 & & 1 \\
\hline 46 & & 1 \\
\hline
\end{tabular}

\begin{tabular}{|l|l|l|}
\hline 89 & & 1 \\
\hline 90 & & 1 \\
\hline 91 & & 1 \\
\hline & & \\
\hline
\end{tabular}

Diperoleh hasil dari posisi cluster 1 adalah C1 berjumlah 4 data dan C2 berjumlah 87 data. Setelah mendapatkan hasil perhitungan iterasi 1, maka selanjutnya menghitung iterasi yang kedua. Dalam hal ini, nilai Centroid yang di gunakan berbeda, harus menghitung nilai Centroid baru dengan cara menjumlahkan nilai cluster yang ada di kolom C1 dan C2 setelah itu dibagi dengan jumlah data itu sendiri..

Berikut perhitungannya :

$$
\begin{aligned}
\mathrm{C} 1 \mathrm{x}= & 2093171+2121888+1554119+960026 / 4=1682301 \\
\mathrm{C} 2 \mathrm{x}= & 595+592+772+27208+4405+2457+56503+4576+48477+610+ \\
& 1784+23455+8695+96139+6620+1909+19904+43721+20345+ \\
& 7569+24447+274117+1265+267823+98272+12600+90022+ \\
& 4776+536902+2167+16301+29400+688+573310+6773+6506+ \\
& 7219+1254+140+5760+4036+3932+6115+8550+1720+618+ \\
& 1381+2668+2173+1030+2414+48133+12821+210426+22838+ \\
& 18615+11424+2035+308977+32704+33223+1859+117532+ \\
& 18787+182086+7054+9264+5264+423191+81690+35669+ \\
& 51417+61191+2328+264278+350+138235+34433+233+32964 \\
& +8387+378131+344766+4057+77466+8453+9896 / 87 \\
= & 61734,39
\end{aligned}
$$

NB : Nilai C1x merupakan nilai penjumlahan data awal yang berdasarkan nilai posisi cluster pada tabel 3.4. disesuaikan dengan nilai 1, jika nilai 1 pada kolom $\mathrm{C} 1$ berada pada urutan 15 maka sesuaikan pada nilai data awal setelah itu dijumlahkan sebanyak nilai 1 yang ada pada kolom C1 dan seterusnya sama dengan $\mathrm{C} 1 \mathrm{y}, \mathrm{C} 2 \mathrm{x}, \mathrm{C} 2 \mathrm{y}$. Dilihat dari tabel posisi Cluster 1 dan tabel posisi Cluster 2 memiliki nilai cluster yang sama dan tidak ada perubahan. Pada penelitian ini, proses perhitungan $K$-Means berhenti pada iterasi ke-2, karena iterasi ke-2 sama hasilnya dengan iterasi sebelumnya. Diperoleh hasil dari posisi Cluster 2 adalah C1 berjumlah 4 data dan C2 berjumlah 87 data maka proses perhitungan dapat dihentikan, sehingga diperoleh kesimpulan sebagai berikut :

1. Cluster 1 (C1) merupakan jumlah kunjungan Wisatawan Mancanegara yang datang ke Indonesia termasuk Cluster tinggi yaitu negara China, Malaysia, Singapore, Timor Leste.

2. Cluster 2 (C2) merupakan jumlah kunjungan Wisatawan Mancanegara yang datang ke Indonesia termasuk Cluster rendah. Dari hasil yang diperoleh, posisi Cluster rendah dapat menjadi masukan kepada pemerintah Indonesia agar lebih memperhatikan jumlah kunjungan Wisatawan Mancanegara yang berkunjung untuk dapat melakukan promosi kepada negara yang tergolong Cluster rendah agar dapat meningkatkan jumlah Wisatawan Mancanegara yang berkunjung ke Indonesia di tahun-tahun yang akan datang. 


\section{HASIL DAN PEMBAHASAN}

\subsection{Pendahuluan}

Pada bab ini menjelaskan tentang hasil dan pembahasan tentang implementasi Software rapidminer versi 5. Data yang digunakan adalah data kunjungan wisatawan manacengara pada tahun 2017 dan 2018. Data set yang terdiri dari 91 negara besar di seluruh dunia. Selanjutnya, data tersebut akan dikelompokkan menggunakan metode K-Means Clustering. Dan diimplementasikan kedalam Software rapidminer versi 5.

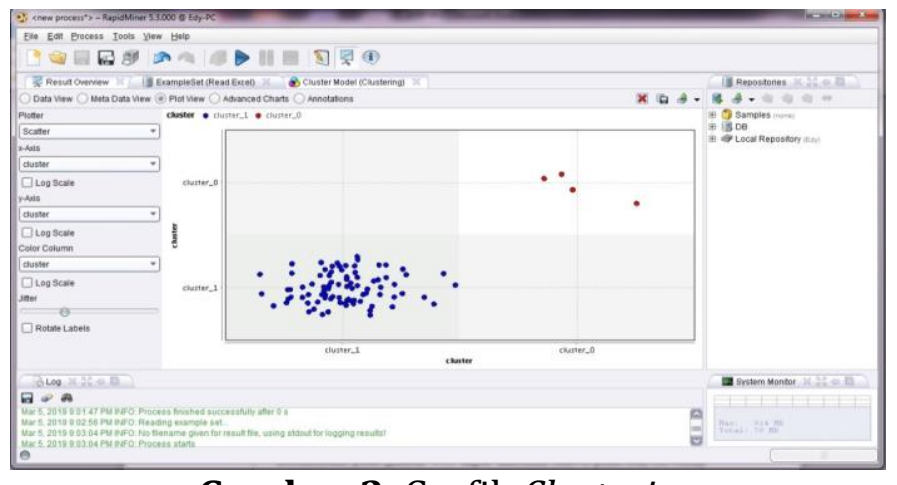

Gambar 2. Grafik Clustering

Berdasarkan pada gambar 2 dapat diketahui bahwa pada titik berwarna merah adalah cluster 0 , titik berwarna biru adalah cluster 1 . Hasil yang diperoleh dari pengklasteran diatas adalah cluster 0 (tinggi) berjumlah 4 Negara yaitu China, Malaysia, Singapore, Timor Leste dan Cluster 1 (rendah) berjumlah 87 Negara.

\subsection{Pembahasan}

Berdasarkan implementasi perhitungan cluster menggunakan Software rapidminer sebelumnya, hasil yang diperoleh adalah jumlah negara yang termasuk cluster tinggi (cluster 0) yaitu negara China, Malaysia, Singapore, Timor Leste. Sedangkan negara yang termasuk cluster rendah (cluster 1) terdapat 87 negara yang tertera pada gambar 4.12. Sama halnya dengan perhitungan manual K-Means menggunakan Microsoft Excel, hasil yang diperoleh pada iterasi 1 dan iterasi 2 terdapat 4 Negara yang termasuk di cluster 1 (cluster 0 pada rapidminer) yaitu negara China, Malaysia, Singapore, Timor Leste dan termasuk di cluster 2 (cluster 1 pada rapidminer) terdapat 87 negara yang hasilnya balance dengan implementasi di rapidminer.

\section{KESIMPULAN}

Berdasarkan hasil perhitungan dan pembahasan Metode K-Means dan implementasi rapidminer pada bab sebelumnya, penulis dapat menarik kesimpulan sebagai berikut.

1. Teknik Data Mining menggunakan algoritma K-Means dapat diterapkan dalam meng-cluster jumlah kunjungan Wisatawan Mancanegara menurut kebangsaan dan bulan kedatangan pada tahun 2017 sampai dengan 2018. 
2. Data yang sebelumnya diolah dalam perhitungan metode K-Means Clustering telah diimplementasikan ke dalam Software rapidminer versi 5 yang bertujuan untuk membuktikan bahwa hasilnya sama dengan perhitungan manual pada metode $K$-Means Clustering.

3. Hasil yang diperoleh dalam meng-cluster jumlah kunjungan Wisatawan Mancanegara menurut kebangsaan dan bulan kedatangan pada tahun 2017 sampai dengan 2018 menggunakan metode $\mathrm{K}$-Means adalah jumlah negara yang termasuk cluster tinggi (cluster 1) 4 negara yaitu negara China, Malaysia, Singapore, Timor Leste. Sedangkan negara yang termasuk cluster rendah (cluster 2) 87 negara. Hasil tersebut sama dengan hasil yang telah diimplementasikan ke dalam Software rapidminer versi 5.

\section{DAFTAR PUSTAKA}

[1] N.Hutasoit, "PENGARUH JUMLAH KUNJUNGAN WISATAWAN MANCANEGARA DAN JUMLAH HUNIAN HOTEL TERHADAP PENERIMAAN SUB SEKTOR PDRB INDUSTRI PARIWISATA DI PROVINSI SUMATERA UTARA TAHUN2004-2013," Mycol. Res., vol. 106, no. 11, pp. 13231330, 2017.

[2] E. G. Sihombing, "Klasifikasi Data Mining Pada Rumah Tangga Menurut Provinsi Dan Status Kepemilikan Rumah Kontrak / Sewa Menggunakan K-Means Clustering Method,” vol. 2, no. 2, pp. 74-82, 2017.

[3] L. Maulida, P. Studi, and M. Informatika, "KUNJUNGAN WISATAWAN KE OBJEK WISATA UNGGULAN DI PROV . DKI JAKARTA DENGAN K-MEANS," vol. 2, no. 3, pp. 167-174, 2018.

[4] M. G. Sadewo, A. P. Windarto, and D. Hartama, "Penerapan Datamining Pada Populasi Daging Ayam Ras Pedaging Di Indonesia Berdasarkan Provinsi Menggunakan K-Means," InfoTekJar (Jurnal Nasional Informatika dan Teknologi Jaringan), vol. 2, no. 1, pp. 60-67, 2017.

[5] A. P. Windarto, "Implementation of Data Mining on Rice Imports by Major Country of Origin Using Algorithm Using K-Means Clustering Method," International Journal of artificial intelligence research, vol. 1, no. 2, pp. 26-33, 2017.

[6] A. P. Windarto, "Penerapan Data Mining Pada Ekspor Buah-Buahan Menurut Negara Tujuan Menggunakan K-Means Clustering," Techno.COM, vol. 16, no. 4, pp. 348-357, 2017.

[7] M. G. Sadewo, A. P. Windarto, and A. Wanto, "Penerapan Algoritma Clustering dalam Mengelompokkan Banyaknya Desa/Kelurahan Menurut Upaya Antisipasi/ Mitigasi Bencana Alam Menurut Provinsi dengan K-Means," KOMIK (Konferensi Nasional Teknologi Informasi dan Komputer), vol. 2, no. 1, pp. 311-319, 2018. 